\title{
Depression Among Delivery Agents and its Determinants due to the COVID-19 Pandemic
}

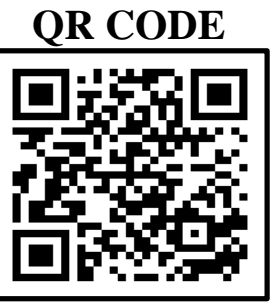

SADAF ANTOO', AFREEN JAN ${ }^{2}$

INTRODUCTION: The outbreak of the COVID-19 Pandemic has led to depression and anxiety in many people.

AIM: To assess depression and its determinants among delivery agents in the Union Territory of Jammu and Kashmir and Punjab State, India.

MATERIALS AND METHOD: The present study was online, cross sectional in nature and was conducted among 1248 delivery agents. The level of depression was assessed using a modified version of the Centre for Epidemiological studies- Depression scale (CES-D). Data analysis was done using descriptive statistics and student's independent t-test followed by the modified Bonferroni post-hoc test applied using SPSS version 21.o. RESULTS: The overall prevalence of depression was found to be $53.7 \%$; Most of the agents belonged to the lower class (59.3\%) and Lower Middle Class $(36.1 \%)$ group. The highest percentage of depression was observed as a result of mortgage ( $91.3 \%$, non-significant), followed by the fear of losing their job (88.8\%) due to the COVID-19 pandemic ( $\mathrm{p}=0.03)$, and fear of getting COVID-19 (85.9\%, non-significant difference). Delivery agents having their own transport seemed to have the lowest depression $(26.7 \%, \mathrm{p}=0.04)$.

CONCLUSION: Based on the results of the present study, governmental and industrial policies towards the benefit of the delivery agents is advised and during these testing times, assurance of job security and paid leaves in case of contracting COVID-19 should be beneficial.

KEYWORDS: COVID-19, Depression, Questionnaire

\section{INTRODUCTION}

The recent COVID pandemic has strained the economy and led to various job losses. ${ }^{1}$ As people were forced to stay in the protection of homes during the lockdown, few essential services were still functional, namely healthcare, police, delivery of essential goods, etc. With a phased "unlock" protocol in India, people preferred to stay indoors and chose to order online for home delivery of goods. These deliveries were undertaken by delivery agents employed by various agencies.

An important fact to understand is the unpredictability of this disease as it leads to loss and control one's freedom. ${ }^{2}$ Such conditions lead to certain mental and social disorders that could disrupt one's activities; and this, coupled with the constant fear of getting sick aggravates/worsens the situation. It has been observed that during pandemics various communities experience stress and anxiety to some extent, and disorders of psychological nature are widespread. ${ }^{3}$ Literature also suggests that people kept in isolation and/or quarantine experience increased levels of anxiety, anger, confusion, and/or stress. ${ }^{4}$

The relationship between environment and the onset of depression and depressive symptoms are more prevalent among workers; especially among those with job stress, low-skill work and a lower job status. ${ }^{5}$ The reasons for the same can be attributed to high expectations from the job, a lesser or lower social support in the workplace, imbalances in effort put and reward(s) gained, job dissatisfaction and fear of losing one's job. ${ }^{6}$

One of the most exposed groups to the COVID-19 virus have been the delivery agents as they deliver packages/food etc from door to door. Not only they have to deliver goods on time, they are constantly on calls, are on the move constantly and are at various risks. Hence, the present study was undertaken with the aim to assess depression and its determinants among delivery agents in the Union Territory of Jammu and Kashmir and Punjab State, India.

\section{MATERIALS AND METHOD}

An online, cross sectional study was conducted by distributing a questionnaire via google forms among various app-based delivery agents (couriers, food delivery, etc) based in the Union Territory of Jammu and Kashmir and Punjab State, India from $25^{\text {th }}$ June, 2020 to $1^{\text {st }}$ December, 2020. Ethical approval was obtained from the study sites prior to data collection, and consent was assumed as completing the survey 
questions. Data was obtained via simple random sampling as well as snowball sampling as the link was distributed to known delivery agents and they were asked to forward the same to their colleagues. Participation in the study was purely voluntary and the delivery agents were free to leave filling the questionnaire at any time. They were assured of the confidentiality of their data and no personal details were collected.

Data was obtained through the modified version of the Centre for Epidemiological studies- Depression scale $(C E S-D)^{7}$, was close ended (pre-validated and pretested) and had a Cronbach's Alpha ( $\alpha$ ) of o.76. The questionnaire was translated and back-translated in Hindi and Punjabi by a language expert. The questionnaire was distributed in both languages (with separate links to both), had 26 questions divided into five sections.

Statistics: Descriptive statistics were applied; data was presented using tables and graphs. The student's independent $t$-test followed by the modified Bonferroni post-hoc test was used to find the association between the variables using SPSS version 21.0.

\section{RESULTS}

At the end of the study period, a total of 1248 completed responses were obtained and their characteristics are shown in table 1 . Most of the delivery agents $(56.2 \%)$ belonged to the age group of $21-30$ years followed by 18-21 years (26.1). Most of the agents belonged to the lower class (59.3\%) and lower middle class (36.1\%).

\begin{tabular}{|c|c|}
\hline Age (In Years) & $\mathbf{n}, \%$ \\
\hline $\mathbf{1 8 - 2 1}$ & $326(26.1)$ \\
$21-30$ & $701(56.2)$ \\
$30-40$ & $211(16.9)$ \\
$>40$ & $10(0.8)$ \\
\hline Socio economic class \\
Upper Class 2 (0.4) \\
Upper Middle 16 (2.8) \\
Middle 187 (32.8) \\
Lower Middle 273(47.9) \\
Lower Class 92 (16.1) \\
\hline Table 1. Distribution of study subjects according to \\
age and socio-economic status \\
\hline
\end{tabular}

The overall percentage of depression among delivery agents was found to be $53.7 \%$, with the highest percentage of depression was observed as a result of mortgage ( $91.3 \%$, non-significant difference), followed by the fear of losing their job (88.8\%) due to the COVID-19 pandemic and it was found to be significant $(\mathrm{p}=0.03)$, and the fear of getting COVID-19 as a result of their job (85.9\%, non-significant difference). Delivery agents having their own transport seemed to have the lowest depression $(26.7 \%, \mathrm{p}=0.04)$ and as seen in table 2.

The sources of loan availed and it's relation with depression in the $563(45.1 \%)$ of delivery agents is depicted in table 3 . Those availing loans from a private lender $(63 \%)$, multiple sources $(62.6 \%)$ and close relative(s) $(50.2 \%)$ showed to have the maximum depression, while the least was depression was observed among those availing loan from a nationalized bank (48.7\%). All the observations were found to be statistically significant $(\mathrm{p}=0.02)$.

\section{DISCUSSION}

Through the findings of the present study, it was revealed that in these COVID-19 times, 53.7\% delivery agents in the Union Territory of Jammu and Kashmir and Punjab State, India were facing a significant amount of depression especially those having loan $(60.2 \%)$ or mortgage (91.3\%). A high percentage of depression was also seen among the delivery agents due the fear of getting COVID-19 or job loss due to it.

The overall percentage of depression was found to be $53.7 \%$ this is on the higher side as compared to farmers $(33.9 \%)^{6}$ and lower in comparison to cab drivers $(60.5 \%)^{8}$ and auto-rickshaw drivers (90\%). ${ }^{9}$ It is to note that the present study was done during the COVID-19 pandemic and hence, the reported percentages of depression could have increased. As per Bueno-Notivol J. et al., a pooled $25 \%$ of depression in community based studies was seven times higher as compared to $3.44 \%$ in 2017 and this does show light on the effect of COVID-19 on the mental health of people. ${ }^{10}$

Only $26.7 \%$ of delivery agents having their own transport reported depression and the association was found to be significant. As per results of a systematic review by Amit $\mathrm{N}$ et al. ${ }^{11}$, evidence was presented to support the unfortunate fact that being in debt is related to depression, anxiety, stress, or suicide ideation among Asian participants. In the same context, farmers who are caught in high debt traps are prone to mental health problems and suicides. ${ }^{6,12}$ 


\begin{tabular}{|c|c|c|c|c|}
\hline \multirow[t]{2}{*}{ Variable } & \multicolumn{2}{|c|}{ Depression } & \multirow[t]{2}{*}{$\mathrm{n}, \%$} & \multirow[t]{2}{*}{ p-value } \\
\hline & Present & Absent & & \\
\hline Overall Depression & $666(53.7)$ & $582(46.3)$ & $1248(100 \%)$ & $0.01^{*}$ \\
\hline $\begin{array}{c}\text { Own Transport } \\
\text { Present } \\
\text { Absent } \\
\end{array}$ & $\begin{array}{c}223(26.7) \\
100(24.3)\end{array}$ & $\begin{array}{l}613(73 \cdot 3) \\
312(75 \cdot 7)\end{array}$ & $\begin{array}{c}836(66.6) \\
412(33.1)\end{array}$ & $0.04^{*}$ \\
\hline $\begin{array}{c}\text { Loan } \\
\text { Present } \\
\text { Absent } \\
\end{array}$ & $\begin{array}{l}339(60.2) \\
201(29 \cdot 3)\end{array}$ & $\begin{array}{l}224(39.8) \\
484(70.7)\end{array}$ & $\begin{array}{l}563(45.1) \\
685(54.9)\end{array}$ & $0.04^{*}$ \\
\hline $\begin{array}{c}\text { Mortgage } \\
\text { Present } \\
\text { Absent }\end{array}$ & $\begin{array}{l}188(91.3) \\
300(24.0)\end{array}$ & $\begin{array}{c}18(8.7) \\
948(76)\end{array}$ & $\begin{array}{c}206(16.5) \\
1042(83.5)\end{array}$ & NS \\
\hline $\begin{array}{c}\text { Fear of getting } \\
\text { COVID-19 } \\
\text { Present } \\
\text { Absent } \\
\end{array}$ & $\begin{array}{c}699(85.9) \\
123(28.3)\end{array}$ & $\begin{array}{l}114(14.1) \\
312(71.7)\end{array}$ & $\begin{array}{c}813(65.1) \\
435(34.9)\end{array}$ & NS \\
\hline $\begin{array}{c}\text { Fear of Loss of Job } \\
\text { (due to COVID-19) } \\
\text { Present } \\
\text { Absent }\end{array}$ & $\begin{array}{l}891(88.8) \\
183(74.7)\end{array}$ & $\begin{array}{l}112(11.2) \\
62(25.3)\end{array}$ & $\begin{array}{c}1003(80.4) \\
245(19.6)\end{array}$ & $0.03^{*}$ \\
\hline
\end{tabular}

Table 2. Illustrating the association between depression and its determinants (Independent samples t-test : Pvalue $<0.05$ is significant)

Fear of contracting COVID-19 and fear of loss of jobs was reported by $85.9 \%$ and $88.8 \%$ of the delivery agents respectively. Threat to job security was predictive of depression and cognitive function in the entire sample such that those with higher levels of perceived job security had lower depression and better cognitive function. This was supported by the findings of Mahmud MS et al. ${ }^{13}$ whose empirical results stated that due to the outbreak of COVID-19, and its fear, people are becoming depressed and anxious about their future career which has been attributed in creating a longterm, negative effect on human psychology.

\begin{tabular}{|c|c|c|c|c|}
\multirow{2}{*}{$\begin{array}{c}\text { Source of } \\
\text { Loan }\end{array}$} & \multicolumn{2}{c}{ Depression } & n,\% & $\begin{array}{c}\text { p- } \\
\text { value }\end{array}$ \\
\hline $\begin{array}{c}\text { Nationalized } \\
\text { Bank }\end{array}$ & $92(48.7)$ & $97(51.3)$ & $189(33.6)$ & \\
$\begin{array}{c}\text { Private } \\
\text { Lender } \\
\text { Multiple }\end{array}$ & $63(63)$ & $37(37)$ & $100(17.8)$ & \\
$\begin{array}{c}\text { Sources } \\
\text { Close }\end{array}$ & $45(62.6)$ & $28(38.4)$ & $73(12.9)$ & O.02* $^{*}$ \\
Relative(s) & $101(50.2)$ & $100(49.8)$ & $201(35.7)$ & \\
\hline
\end{tabular}

Table 3. Association between source of loan and depression

This study is prone to certain limitations, the first being the limited number of literature on the effects of
COVID-19 on depression among people. A comprehensive literature search did not reveal any study pertaining to depression among delivery agents. Therefore, comparisons were made with other populations sharing almost the same experience (cab drivers, truck drivers, farmers, etc). Second, due to the self-reported nature of the questionnaire, it is possible that the delivery agents might have either "under" or "over" reported their feelings regarding depression. However, due to the nature of the study and keeping various factors in account (data taken from delivery agents pan-India, assurance of data confidentiality, voluntary participation), the results can be generalized for all delivery riders.

\section{CONCLUSION}

The results of the present study showed that depression among delivery agents is on the higher side and in light of the current pandemic situation, the government and employers should keep certain checks in place, assure the delivery agents regarding their job, thus alleviating future "job-related anxiety". The riders should be provided with financial assistance and "paid" leaves in case they contract COVID-19 while performing their duty with due diligence.

\section{REFERENCES}

1. WHO. The impact of the COVID-19 pandemic on jobs and incomes in G2o economies. (Online PDF). 
Available

https://www.ilo.org/wcmsp5/groups/public/--dgreports/---

cabinet/documents/publication/wcms 756331.pdf. [Last Accessed on $15^{\text {th }}$ January, 2021]

2. Huremović D. Social Distancing, Quarantine, and Isolation. In: Huremović D., editor. Psychiatry of Pandemics. Springer International Publishing; 2019. pp. 85-94.

3. Al Omari O, Al Sabei S, Al Rawajfah O, Sharour LA, Aljohani K, Alomari K, et al. Prevalence and Predictors of Depression, Anxiety, and Stress among Youth at the Time of COVID-19: An Online Cross-Sectional Multicountry Study. Depression Research and Treatment $\quad 2020 \quad$;2020: $\quad 8887727$. https://doi.org/10.1155/2020/8887727

4. Brooks SK, Webster RK, Smith LE, Woodland L, Wessely S, Greenberg N, et al. The psychological impact of quarantine and how to reduce it: rapid review of the evidence. Lancet. 2020. 14;395(10227):912-20. https://doi.org/10.1016/So140-6736(20)3046o-8.

5. Hussien G, Tesfaye M, Hiko D, Fekadu H. Assessment of Prevalence and Risk Factors of Depression among Adults in Gilgel Gibe Field Research Center, South West Ethiopia. Journal of Depression and Anxiety. J Depress Anxiety. 2017;6(1):100026o. https://doi.org/10.4172/2167-1044.100026o

6. Ahmed MT, Jadhav J, Vishwanatha. Prevalence of Depression among the Farmers and its Determinants: A Cross Sectional Study. Natl J Community Med. 2019;10(8):466-9.
7. Radloff LS. The CES-D scale: A self-report depression scale for research in the general population. Appl Psychol Meas. 1977;1:385-401 Cross-Sectional Study of Prevalence of Depression, New Delhi. Indian Journal of Occupational and Environmental Medicine 2019; 23: 48-53. https://doi.org/10.4103/ijoem.IJOEM_158_18

9. Kaul S, Gupta AK, Sarkar T, Ahsan SK, Singh NP. Substance abuse and depression among auto-rickshaw drivers: A study from the national capital region of Delhi, India. Indian J Med Spec 2019;10:143-8. https://doi.org/10.4103/INJMS.INJMS_64_19

10. Bueno-Notivol J, Gracia-García P, Olaya B, Lasheras I, López-Antón R, Santabárbarac J. Int J Clin Health Psychol. 2021; 21(1): 100196. 10.1016/j.ijchp.2020.07.007 11. Amit N, Ismail R, Zumrah AR, Nizah MAM, Muda TEAT, Meng ECT, et al. Relationship Between Debt and Depression, Anxiety, Stress, or Suicide Ideation in Asia: A Systematic Review. Front Psychol. 2020; 11: 1336. https://doi.org/10.3389/fpsyg.2020.01336

12. Sathyanarayana Rao T S, Gowda MR, Ramachandran K, Andrade C. Prevention of farmer suicides: Greater need for state role than for a mental health professional's role. Indian J Psychiatry. 2017;59:3-5.

13. Mahmud MS, Talukder MU, Rahman SM. Does 'Fear of COVID-19' trigger future career anxiety? An empirical investigation considering depression from COVID-19 as a mediator. Int J Soc Psychiatry. 2020:1-11. https://doi.org/10.1177/0020764020935488.
8. Akanksha R, Vikas K, Singh A, Pannalal, A Anxiety and Stress among Professional Cab Drivers in
Cite this article as:

Antoo S, Jan A.

COVID-19

https://doi.org/10.26440/IHRJ/0501.04401
Depression Among Delivery Agents and its Determinants due to the Healthc Res J. 2021;5(1)OR1-OR4

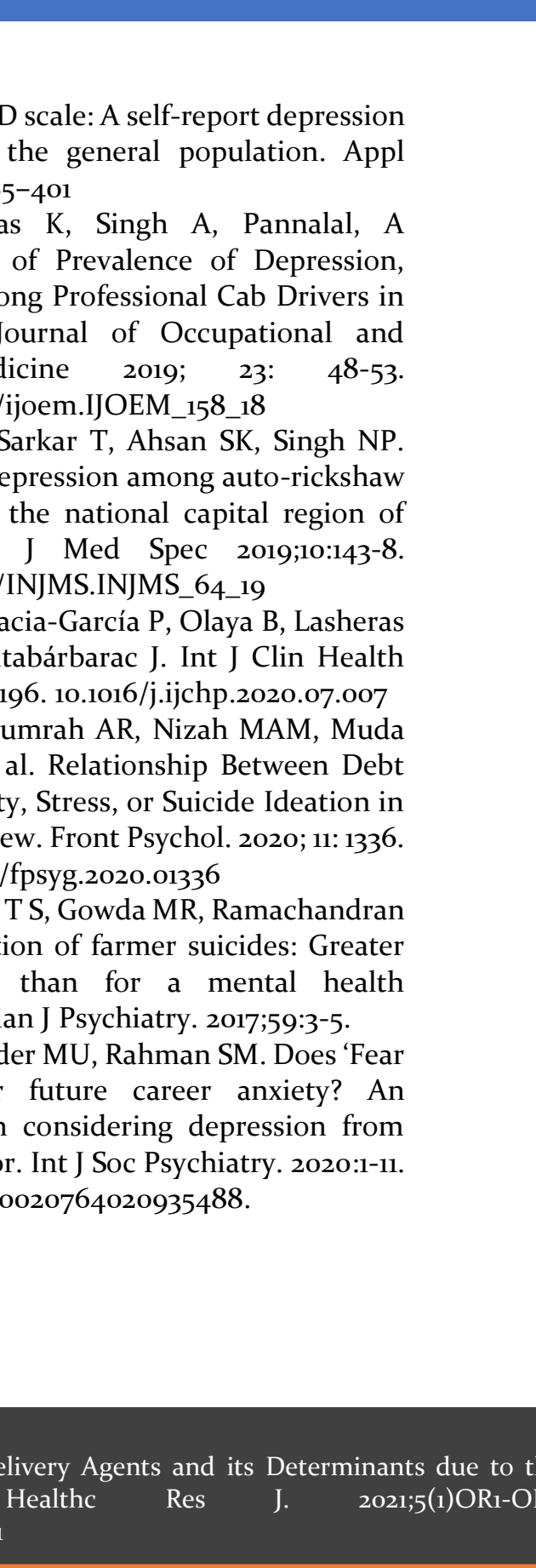

\section{AUTHOR AFFILIATIONS: $\left({ }^{*}\right.$ Corresponding Author)}

1. Resident, Department of Oral and Maxillofacial Surgery and Dentistry, SKIMS Medical College and Hospital, Bemina Srinagar, Jammu \& Kashmir

2. PG Student, Department of Oral and Maxillofacial Pathology and Microbiology, ITS CDSR Ghaziabad; Senior Research Fellow at ICMR, Delhi

Source of support: Nil, Conflict of interest: None declared

Contact Corresponding Author at: zoyareen[at]gmail[dot]com 